\title{
Correlation of orthodontic treatment motivation and the level of treatment needs based on the index of orthodontic treatment need (IOTN) of orthodontic patients
}

\author{
Rissa Zharfany Ernata ${ }^{1 *}$, Gita Gayatri ${ }^{1}$, Anne Agustina Suwargiani² \\ ${ }^{1}$ Department of Orthodontics, Faculty of Dentistry Universitas Padjadjaran, Indonesia \\ ${ }^{2}$ Department of Dental Public Health, Faculty of Dentistry Universitas Padjadjaran, Indonesia
}

\begin{abstract}
Introduction: Malocclusion has an impact on the quality of life, thus becoming the motivation for orthodontic treatment. Subjective and objective needs for orthodontic treatment vary, where subjective needs are sometimes higher or maybe lower than objective needs, vice versa. The Index of Orthodontic Treatment Need (IOTN) is an index used to see the level of treatment needs. This study was aimed to analyse the correlation of orthodontic treatment motivation and the level of treatment needs based on the index of orthodontic treatment need (IOTN) of orthodontic patients. Methods: The research was correlation analytical. The motivation for orthodontic treatment was assessed using a questionnaire consisted of aspects of oral health motivation, oral function, aesthetics, psychosocial, and influence from others. The level of orthodontic treatment needs was assessed using the IOTN dental health component. Results: It was found that the patients' motivation related to aesthetics was high. The motivation to get orthodontic treatment due to oral health, oral function, and psychosocial conditions was moderate, while related to the influence of others was low. The level of need for grade 4 treatment shows the largest percentage (48.57\%). Gamma correlation analysis between motivation variables related to the oral and psychosocial function with the level of treatment needs showed a significantly positive correlation with the p-values of 0.003 and 0.022 , categorized as weak correlation. Conclusion: There is a weak correlation of orthodontic treatment motivation and the level of treatment needs based on the index of orthodontic treatment need (IOTN) of orthodontic patients.
\end{abstract}

Keywords: Aesthetics, Index of orthodontic treatment need, oral health, motivation, level of orthodontic treatment need.

p-ISSN: 1979-0201; e-ISSN: 2549-6212; Available from: http://jurnal.unpad.ac.id/pjd/article/view/24844

DOI: $10.24198 /$ pjd.vol32no3.24844

Submission: Nov 28, 2019; Accepted: Oct 1, 2020; Published online: Nov 30, 2020

"Corresponding author: Rissa Zharfany Ernata, Department of Orthodontics, Faculty of Dentistry Universitas Padjadjaran, Indonesia. Department of Orthodontics, Faculty of Dentistry Universitas Padjadjaran, Jalan Sekeloa Selatan I, Bandung, West Java, Indonesia, 40132. Phone: +6287821188897; Email: rissa15001@mail.unpad.ac.id 


\section{INTRODUCTION}

Malocclusion is a condition of oral health which can affect oral function, appearance, interpersonal relationships, social life, self-esteem, and an individual's psychological condition. Malocclusion differs from the majority of medical and dental conditions in that it is a set of dental deviations rather than a disease. ${ }^{1}$ The prevalence of malocclusion in Indonesia reaches $80 \%$ of the population. ${ }^{2}$ Malocclusion is a factor in the scope of oral health that has an impact on the quality of life. ${ }^{3}$

Research conducted by George et al. ${ }^{4}$ demonstrated that malocclusion has an impact on psychological discomfort, physical pain, and function limitation, which are the three highest domains of the Oral Health Impact Profile. Literature review written by Samsonyanova et al. ${ }^{5}$ explained that an individual's quality of life is determined by various things such as health, function, aesthetics, and social interactions. The results of research conducted by Kavaliauskiene et al. ${ }^{6}$ showed a negative relationship between quality of life as measured by OHRQoL (Oral Health-Related Quality of Life) and the level of orthodontic care treatment need as measured by the IOTN. This study shows that the higher the orthodontic care treatment need, the lower the OHRQoL value will be. ${ }^{6}$

Orthodontic treatment is a method of aligning the teeth or correcting other irregularities, which can improve health, oral function, appearance, and social well-being. ${ }^{7}$ Orthodontic treatment is often performed by patients in the hope of getting dental appearance and function improvement. ${ }^{7}$ The main reasons that are usually used to obtain orthodontic treatment are to improve the teeth function, oral health, and the aesthetical aspect of the teeth and face. ${ }^{8} \mathrm{An}$ individual's motivation in performing orthodontic treatment can affect the success of the treatment because, with strong motivation, a person wants to achieve a goal thus will affecting the adherence in orthodontic treatment. $^{7}$

The objective (normative) and subjective need for orthodontic treatment varies from person to person. Research conducted by Rampersadh ${ }^{9}$ showed that the normative demands of patients for orthodontic treatment were higher than those based on patient perceptions. Another study by Ravindranath et al. ${ }^{10}$ suggested that the needs based on the patient's perception are higher than the normative needs. The study showed that the need for orthodontic treatment determined by an index assessment did not necessarily reflect the patient's perception of the need for such treatment. ${ }^{10}$

The severity of malocclusion can determine the need for orthodontic treatment. ${ }^{11}$ The orthodontic treatment need index can identify the patient's need for orthodontic treatment and also determine the priority of orthodontic treatment. One of the indexes commonly used is the index of orthodontic treatment need (IOTN) which consists of aesthetic component (AC) as a subjective component and dental health component (DHC) as an objective component. The two components are assessed separately. ${ }^{12}$ IOTN is a valid and reliable index. ${ }^{13}$

The period of epidemiological surveys using this index is relatively short because it determines the level of need for orthodontic treatment based on the most severe conditions. ${ }^{14}$ This study was aimed to analyse the coerelation of patients' motivation in getting orthodontic treatment and the level of treatment needs using dental health components $(\mathrm{DHC})$ in the index of orthodontic treatment need (IOTN).

\section{METHODS}

This research was correlation analytic, conducted at the Orthodontics Dental Specialist Education Program (PPDGS) Polyclinic of Universitas Padjadjaran Dental Hospital. The sampling technique used was the total sampling technique from a population of patient subjects who were indicated to receive orthodontic treatment, had never received orthodontic treatment before, and did not use fixed or removable orthodontic appliances, which obtained a sample of 35 respondents.

The patient's motivation for orthodontic treatment was measured using a questionnaire that has been tested for validity and reliability, where the validity test value of each question has a score above 0.300 (using a correlation measurement between each question and the total value of all questions) which indicated 
that each question on the questionnaire was valid. The reliability test showed the Cronbach's Alpha value of 0.839 , which indicated that the questions in the questionnaire were very reliable.
The level of need for orthodontic treatment was obtained through a clinical examination using the Dental Health Component (DHC) in the Index of Orthodontic Treatment Need (IOTN).

Table 1. Dental Health Components (DHC) of the IOTN ${ }^{13}$

\begin{tabular}{|c|c|}
\hline Grade & Treatment need criteria \\
\hline Grade 5 & Very great need \\
\hline $5 i$ & $\begin{array}{l}\text { Impeded eruption of teeth (with the exception of third molars) due to crowding, displacement, the presence of } \\
\text { supernumerary teeth, retained deciduous teeth and any pathological cause. }\end{array}$ \\
\hline $5 \mathrm{~h}$ & $\begin{array}{l}\text { Extensive hypodontia with restorative implications (more than one tooth missing in any quadrant) requiring pre- } \\
\text { restorative orthodontics. }\end{array}$ \\
\hline $5 a$ & Increased overjet > $9 \mathrm{~mm}$. \\
\hline $5 m$ & Reverse overjet greater than $3.5 \mathrm{~mm}$ with reported masticatory and speech difficulties. \\
\hline $5 p$ & Defect of cleft lip and palate/craniofacial anomalies. \\
\hline $5 s$ & Submerged deciduous teeth. \\
\hline
\end{tabular}

\section{Grade 4 Great need}

$4 \mathrm{~h} \quad$ Less extensive hypodontia requiring pre-restorative orthodontics or orthodontic space closure to obviate the need for a prosthesis.

4a Increased overjet $>6 \mathrm{~mm}$ but $\leq 9 \mathrm{~mm}$.

4b Reverse overjet $>3.5 \mathrm{~mm}$ with no masticatory or speech difficulties.

$4 \mathrm{~m} \quad$ Reverse overjet greater than $1 \mathrm{~mm}$ but $\leq 3.5 \mathrm{~mm}$ with recorded masticatory and speech difficulties.

4c Anterior or posterior crossbites with $>2 \mathrm{~mm}$ discrepancy between retruded contact position and intercuspal position.

4l Posterior lingual crossbite (scissors bite) with no functional occlusal contact in one or both buccal segments.

4d Severe contact point displacements of teeth $>4 \mathrm{~mm}$.

$4 \mathrm{e} \quad$ Extreme lateral or anterior open bites $>4 \mathrm{~mm}$.

$4 \mathrm{f} \quad$ Increased and complete overbite with gingival or palatal trauma.

4t Partially erupted teeth, tipped and impacted against adjacent teeth.

$4 \mathrm{x} \quad$ Presence of supernumerary (e.g. Supplemental teeth).

\section{Grade 3 Borderline need}

Increased overjet $>3.5 \mathrm{~mm}$ but $\leq 6 \mathrm{~mm}$ with incompetent lips.

bb Reverse overjet greater than $1 \mathrm{~mm}$ but $\leq 3.5 \mathrm{~mm}$.

3c Anterior or posterior crossbites with $>1 \mathrm{~mm}$ but $\leq 2 \mathrm{~mm}$ discrepancy between retruded contact position and intercuspal position.

3d Contact point displacement of teeth $>2 \mathrm{~mm}$ but $\leq 4 \mathrm{~mm}$.

3e $\quad$ Lateral or anterior open bite greater than $2 \mathrm{~mm}$ but $\leq 4 \mathrm{~mm}$.

3f Increased and complete overbite without gingival or palatal trauma.

\section{Grade 2 Little need}

2a Increased overjet $>3.5 \mathrm{~mm} \leq 6 \mathrm{~mm}$ with competent lips.

2b Reverse overjet $>0 \mathrm{~mm}$ but $\leq 1 \mathrm{~mm}$.

2c Anterior or posterior crossbite with $\leq 1 \mathrm{~mm}$ discrepancy between retruded contact position and intercuspal position.

2d Contact point displacement of teeth $>1 \mathrm{~mm}$ but $\leq 2 \mathrm{~mm}$.

2e $\quad$ Anterior or posterior open bite $>1 \mathrm{~mm}$ but $\leq 2 \mathrm{~mm}$.

$2 f \quad$ Increased overbite $\geq 3.5 \mathrm{~mm}$ without gingival contact.

$2 \mathrm{~g} \quad$ Pre-normal or post-normal occlusions with no other anomalies. Includes up to half a unit discrepancy.

Grade 1 No need, Extremely minor malocclusions including displacements $\leq 1 \mathrm{~mm}$. 
The questionnaire contained questions that lead to respondents' motivation in getting orthodontic treatment related to oral health, oral function, aesthetics, psychosocial, and motivation that arise due to influence from others. The results of the average answer score obtained from the orthodontic treatment motivation questionnaire were categorised as low (average value 1 to 2 ), moderate (average value $>2$ to 3 ), and high (average value $>3$ to 4 ), based on the measurement of the interval class length from Sturgess. The IOTN DHC assesses the need for orthodontic treatment based on several characteristics. The characteristics evaluated include the shift in contact points, overjet, overbite, reverse overjet/crossbite, open bite, an abnormal number of teeth, impacted teeth, tooth eruption, and the presence of cleft lip and palate

\section{RESULTS}

The number of samples obtained was 35 respondents, consisting of $28.57 \%$ male and $71.43 \%$ female respondents. Respondents aged of 15 to conditions. The level of need for care will be categorised according to the DHC classification. The IOTN will be classified into five grades ranging from grade one (no need for treatment) to grade five (very great need of treatment) (Table 1). ${ }^{13}$ Only DHC component used in this study because the researcher used another research instrument in the form of a questionnaire to obtain the patient's subjective assessment of the motivation for orthodontic treatment.

Data collected were processed using gamma correlation analysis afterwards to see the relationship between the two variables. The research was conducted after getting ethical approval from the Health Research Ethics Committee of the Faculty of Medicine Universitas Padjadjaran, with the number of 1442 / UN6.KEP/ EC/2018.

25 years were $85.71 \%$, while respondents aged of 26 to 50 years were $14.29 \%$. The results showed that the highest motivation was motivation related to aesthetics, with an average score of 3.38. The motivation for orthodontic treatment

Table 2. Motivation of respondents in getting orthodontic treatment

\begin{tabular}{lcccc}
\hline \multirow{2}{*}{ Motivation } & & & & \\
\cline { 2 - 4 } & Lowest & Mean & Highest & Category \\
\hline Oral health & 1.67 & 2.83 & 4.00 & Moderate \\
Oral function & 1.33 & 2.10 & 3.67 & Moderate \\
Aesthetics & 2.33 & 3.38 & 4.00 & High \\
Psychosocial & 1.67 & 2.73 & 4.00 & Moderate \\
Influence of others & 1.00 & 1.70 & 2.50 & Low \\
\hline
\end{tabular}

Table 3. The need for care level based on the IOTN DHC

\begin{tabular}{lcc}
\hline \multicolumn{1}{c}{ Need for care level } & $\mathrm{n} \mathrm{( \% )}$ & $\%$ \\
\hline 1 (No need for treatment) & 0 & 0 \\
2 (Little need for treatment) & 6 & 17.14 \\
3 (Borderline need for treatment) & 7 & 20.00 \\
4 (Great need for treatment) & 17 & 48.57 \\
5 (Very great need for treatment) & 5 & 14.29 \\
\hline
\end{tabular}

Table 4. Analysis of the gamma-correlation between motivation and the need for care level

\begin{tabular}{lcc}
\hline & \multicolumn{2}{c}{ Relationship with the need for care level } \\
\cline { 2 - 3 } & Gamma & P-value \\
\hline Oral health & 0.142 & 0.367 \\
Oral function & 0.481 & $0.003^{* *}$ \\
Aesthetics & 0.202 & 0.388 \\
Psychosocial & 0.442 & $0.022^{* *}$ \\
Influence of others & 0.061 & 1.000 \\
\hline
\end{tabular}


due to the influence of other people was the lowest motivation, which indicated by an average score of 1.70. Respondents indicated the level of need for grade 4 care was $48.57 \%$, while $14.29 \%$ of respondents indicated the level of need for grade 5 care. The result showed that most of the respondents have a great need for orthodontic treatment.

The motivation variable which significantly related to the need for care level was indicated by a p-value less than 0.05 . Motivation related to oral and psychosocial function showed a relationship with the need for care level. The gamma coefficient on the three motivation variables showed a positive number. Thus the direction of the relationship was positive, that is, if the motivation to get orthodontic treatment increases, then the need for orthodontic treatment will also increase, vice versa.

\section{DISCUSSION}

The patient's motivation in seeking orthodontic treatment is essential for treatment success. Patient's expectations of the achieved results from orthodontic treatment, as well as patient's enthusiasm, are needed in planning orthodontic treatment. ${ }^{15}$ Effective treatment can be carried out if the operator/dentist know and understand the expectations and difficulties of the patient, and the patient's motivation in seeking orthodontic treatment, to adjusting the treatment by the patient's needs. Aesthetic motivation is the highest motivation in getting orthodontic treatment.

This result is supported by previous research of Jayachandar et al. ${ }^{17}$, which stated that in general, aesthetic improvement is the improvement most patients expect after treatment, which is $83 \%$. Aesthetics is an essential factor in getting orthodontic treatment because most of the subjects suggested that the primary motivation for getting orthodontic treatment was to correct the teeth alignment and improve general aesthetics. ${ }^{18}$ Jayachandar et al. ${ }^{17}$ stated that individuals seeking orthodontic treatment are individuals who feel dissatisfied with their appearance. Individual awareness and satisfaction with their appearance can influence orthodontic treatment. ${ }^{17}$ The motivation for getting an orthodontic treatment based on the influence of others was low. This condition was supported by previous research conducted by Agarwal et al. ${ }^{19}$, which showed that as many as $55 \%$ of respondents want to get orthodontic treatment solely due to their needs. Motivation sources are essential in determining satisfaction with the orthodontic treatment results. $^{20}$ Motivation dominated by external motivation can result in a lack of satisfaction with treatment outcomes.

Most of the respondents have a highlevel need for treatment. The level of need for treatment was assessed using the dental health component $(\mathrm{DHC})$ in the index of orthodontic treatment need (IOTN). The results of this study was also supported by previous research conducted by Ouedraogo et al. ${ }^{22}$, which demonstrated that 91.4\% of adolescent patients visiting orthodontic clinics required orthodontic treatment. Also, another study by Nobile et al. ${ }^{23}$ showed that $59.5 \%$ of the respondents, children and adolescents, belong to the grade 4 and 5.23 level of treatment needs.

The results showed that there was a relationship between oral function related motivation and the level of treatment needs. Proffit et al. ${ }^{12}$ also stated that there is a positive relationship between limited oral function and the severity of malocclusion. Several oral functions can be impaired due to malocclusion are mastication and speech function. Malocclusion may not disable the oral function overall, but it can cause difficulties performing the functions. ${ }^{12}$

Abraham Maslow's hierarchical system of needs reveals the level of individual needs. ${ }^{24}$ Physiological needs (one of which is the need to eat) and social needs are included in the hierarchical system. ${ }^{24,25}$ Each individual will try to take action to achieve their needs. ${ }^{25} \mathrm{Also}$, there is a social health environmental model which assumes that the state of health is indicated by optimal functioning and good social and psychological well-being. The social science paradigm or aspects of health in quality of life focus on the functional dimensions, welfare and individual ability to carry out their role in the social life. ${ }^{26}$

These things also underlie the relationship that occurs between motivation related to psychosocial conditions and the level of treatment need. Previous research conducted by Bellot-Arcis et al. ${ }^{27}$ stated that malocclusion has an impact on 
a person's psychosocial condition, and this impact increases with the severity of the malocclusion. The psychosocial impact is the influence of selfconfidence and social life. ${ }^{27} \mathrm{~A}$ personal assessment of his/her characteristics can be an impetus for that person to do something, but social conditions are a more decisive determinant factor. ${ }^{28}$

There is no significant correlation between oral health-related motivation and the level of treatment need. Research conducted by Kamble et al. ${ }^{29}$ explained that individual awareness of oral health varies, thus affecting individual oral hygiene behaviour. Research conducted by Al-Qurashi et al. ${ }^{30}$ showed that there are no significant differences regarding oral health behaviour between the group of subjects with normal occlusion (few malocclusions) and a group of subjects with many characteristics of malocclusion. The study also showed that there is no difference regarding oral pain between the two groups. ${ }^{30}$

The relationship between aestheticsrelated motivation and level of treatment need was not found in the present study. Athira et al. ${ }^{31}$ said that perception of the appearance is very subjective. Perception is a process where patterns of environmental stimuli are processed and interpreted, thus can be influenced by physical, psychological, and social factors. ${ }^{31}$ Yilmaz et al. ${ }^{32}$ stated that perceptions of aesthetics could depend on several factors such as behaviour, social environment, and economic status. Perceptions can also vary between individuals, race, and sex..$^{31}$ Perceived aesthetics, and occlusion standards may differ between patients and their surrounding community. ${ }^{33}$

The results of the present study showed that there was no relationship between motivation caused by the influence of others and the level of treatment need. Research conducted by Silva et al. ${ }^{34}$ suggested that self-perception of orthodontic treatment need is related to the quality of life. Research conducted by Kavaliauskiene et al. ${ }^{6}$ and Dalaie et al. ${ }^{35}$ showed that the level of treatment need and the severity of malocclusion are related to the impact on the quality of life.

Subjects who are motivated to receive orthodontic treatment due to the influence of others do not consider perceptions regarding their quality of life. External motivation arises due to the factors that generate the will/desire as a consequence of something. Factors that establish external motivation do not create will/desire to fulfil self-interest. ${ }^{36}$

\section{CONCLUSION}

There is a weak correlation of orthodontic treatment motivation and the level of treatment needs based on the index of orthodontic treatment need (IOTN) of orthodontic patients.

\section{REFERENCES}

1. Masood Y, Masood M, Zainul NN, Araby NAA, Hussain SF, Newton T. Impact of malocclusion on oral health related quality of life in young people. Health Qual Life Outcomes. 2013; 11: 25-30. DOI: 10.1186/1477-7525-11-25

2. Susilowati. The prevalence of anterior dental malocclusion on elementary school students (A preliminary study in SD 6 Maccora Walihe, Sidrap). Makassar Dent J. 2016; 5(3): 97-101.

3. Araki M, Yasuda $\mathrm{Y}$, Ogawa $\mathrm{T}$, Tumurkhuu $\mathrm{T}$, Ganburged G, Bazar A, et al. Associations between malocclusion and oral health-related quality of life among Mongolian adolescents. Int J Environ Res Public Health. 2017; 14(8): 902. DOI: $10.3390 /$ ijerph14080902

4. George R, Samson RS, Soe HHK, Donald PM, Hui WL, Ling PK, et al. Oral health-related quality of life and the index of orthodontic treatment need to evaluate the association of patients ' self-perceived need and normative need toward orthodontic treatment. J Int Oral Health. 2018; 10(3): 115-20. DOI: 10.4103/ jioh.jioh_64_18

5. Samsonyanová L, Broukal Z. A systematic review of individual motivational factors in orthodontic treatment: Facial attractiveness as the main motivational factor in orthodontic treatment. Int J Dent. 2014; 2014: 1-7.

6. Kavaliauskienè A, Šidlauskas A, Zaborskis A. Relationship between orthodontic treatment need and oral health-related quality of life among 11- 18-year-old adolescents in Lithuania. Int J Environ Res Public Health. 2018; 15(5): 1012. DOI: 10.3390/ijerph15051012

7. Tang $X$, Cai J, Lin B, Yao L, Lin F. Motivation of adult female patients seeking orthodontic 
treatment: An application of Q-Methodology. Patient Prefer Adherence. 2015; 9: 249-56. DOI: $10.2147 /$ PPA.S78691

8. Yao J, Li DD, Yang YQ, McGrath CPJ, Mattheos N. What are patient's expectations of orthodontic treatment: A systematic review. BMC Oral Health. 2016; 16: 19-26. DOI: 10.1186/s12903-016-0182-3

9. Rampersadh Y. The Perceived and Normative Orthodontic Treatment Need of A Group of South African children [thesis]. Cape Town: University of the Western Cape; 2015.

10. Ravindranath S, En JTS, Heng APK. Orthodontic treatment need and self-perceived psychosocial impact of dental esthetics in a university adult population in Malaysia. $J$ Indian Orthod Soc. 2017; 51(2): 69-74. DOI: 10.4103/jios.jios_214_16

11. Awad R, Abuaffan AH. Prevalence of malocclusion in a sample of Sudanese university students by the index of orthodontic treatment need index (IOTN). EC Dent Sci. 2018; 17(1): 15-22.

12. Proffit WR, Fields HW, Sarver DM. Contemporary Orthodontics. $4^{\text {th }}$ ed. St. Louis: Mosby-Elsevier; 2007. p. 4-21.

13. Borzabadi-Farahani A. An Overview Of Selected Orthodontic Treatment Need Indices. In: Naretto S. Principles in Contemporary Orthodontics. London: InTech Open; 2011. p. 215-36.

14. Cardoso CF, Drummond AF, Lages EMB, Pretti $\mathrm{H}$, Ferreira EF, Abreu MHNG. The dental aesthetic index and dental health component of the index of orthodontic treatment need as tools in epidemiological studies. Int J Environ Res Public Health. 2011; 8(8): 3277-86. DOI: 10.3390/ijerph8083277

15. Wedrychowska-Szulc B, Syryńska M. Patient and parent motivation for orthodontic treatment - A questionnaire study. Eur J Orthod. 2010; 32(4): 447-52. DOI: 10.1093/ ejo/cjp131

16. Oliviera PGDSA, Tavares RR, Freitas JC. Assessment of motivation, expectations and satisfaction of adult patients submitted to orthodontic treatment. Dental Press J Orthod. 2013; 18(2): 81-7. DOI: 10.1590/s217694512013000200018

17. Jayachandar D, Dinesh SPS. Factors affecting patient's desire for seeking orthodontic treatment. Int J Orthod Rehabil. 2016; 7(3): 89-91. DOI: $10.4103 / 2349-5243.192528$

18. Mahajan M. Evaluation of different motivational factors for seeking orthodontic treatment: The patient's and parent's response. J Dent Allied Sci. 2018; 7(2): 55-9. DOI: $10.4103 /$ jdas.jdas_14_17

19. Agarwal G, Ingle NA, Kaur N, Yadav P, Ingle E, Charania Z. Expressed needs associated with orthodontic treatment in a private dental college, Mathura. J Indian Assoc Public Health Dent. 2015; 13(2): 158-62. DOI: 10.4103/2319$\underline{5932.159054}$

20. Pabari S, Moles DR, Cunningham SJ. Assessment of motivation and psychological characteristics of adult orthodontic patients. Am J Orthod Dentofacial Orthop. 2011; 140(6): 263-72. DOI: $10.1016 / j$.ajodo.2011.06.022

21. Feldens CA, Nakamura EK, Tessarollo FR, Closs LQ. Desire for orthodontic treatment and associated factors among adolescents in Southern Brazil. Angle Orthod. 2015; 85(2): 224-32.

22. Ouédraogo $Y$, Camara T, Bationo R, Bahije L, Beugré JB, Diouf JS, et al. Prevalence of malocclusions and normative orthodontic treatment need using IOTN index for patients in Yalgado Ouédraogo Teaching Hospital. Open J Stomatol. 2017; 7(12): 519-29. DOI: $10.4236 /$ ojst.2017.712049

23. Nobile CGA, Pavia M, Fortunato L, Angelillo IF. Prevalence and factors related to malocclusion and orthodontic treatment need in children and adolescents in Italy. Eur J Public Health. 2007; 17(6): 637-41. DOI: 10.1093/eurpub/ $\mathrm{ckm016}$

24. Thielke S, Harniss $M$, Thompson $H$, Patel $S$, Demiris G, Johnson K. Maslow's hierarchy of human needs and the adoption of healthrelated technologies for older adults. Age Int. 2012; 37: 470-88. DOI: 10.1007/s12126-0119121-4

25. Burton K. A Study of Motivation: How to Get Your Employees Moving [thesis]. Bloomington: Indiana University; 2012.

26. Baiju RM, Peter ELBE, Varghese NO, Sivaram R. Oral health and quality of life: Current concepts. J Clin Diagn Res. 2017; 11(6): ZE21ZE26. DOI: $10.7860 / J C D R / 2017 / 25866.10110$ 
27. Bellot-Arcís C, Montiel-Company JM, Almerich-Silla JM. Psychosocial impact of malocclusion in Spanish adolescents. Korean J Orthod. 2013; 43(4): 193-200. DOI: $10.4041 /$ kjod.2013.43.4.193

28. Rachmawati A, Sufarnap E. The relationship between orthodontic treatment need and psychosocial impact in University of Sumatera Utara undergraduate student. Adv Health Sci Res. 2018; 8: 1-3.

29. Kamble VS, Biradar SM, Takpere A, Reddy S. Evaluation of oral hygiene awareness and practices among medical students. Int $\mathrm{J}$ Comm Med Public Health. 2016; 3(1): 83-5. DOI: 10.18203/2394-6040.ijcmph20151221

30. Al-Qurashi H, Al-Farea M, Alshamrani HA, Almasoud NN, Nazir MA. Orthodontic treatment needs and association between malocclusion and oral hygiene behavior. Pak Oral Dent J. 2018; 38(1): 62-6.

31. Athira S, Jayakumar HL, Chandra M, Gupta T, Anand PJS, Dithi C. Dental esthetic perceptions and orthodontic treatment needs among school children aged $9-18$ years of South Bengaluru: A cross-sectional study. J Ind Assoc Public Health Dent. 2016; 14(1): 50-6. DOI: $\underline{10.4103 / 2319-5932.178724}$
32. Yilmaz RBN, Oktay I, Ithan D, Fisekcioglu E, Ozdemir F. Normative and subjective need for orthodontic treatment within different age groups in a population in Turkey. Niger J Clin Pract. 2017; 20(12): 1632-8. DOI: 10.4103/1119-3077.224126

33. Navabi N, Farnudi H, Rafiei H, Arashlow MT. Orthodontic treatment and the oral healthrelated quality of life of patients. J Dent (Tehran). 2012; 9(3): 247-54.

34. e Silva LFG, Thomaz EBAF, Freitas HV, Pereira ALP, Ribeiro CCC, Alves CMC. Impact of malocclusion on the quality of life of Brazilian adolescents: A population-based study. PLoS One. 2016; 11(9): 1-13. DOI: 10.1371/journal. pone. 0162715

35. Dalaie K, Behnaz M, Khodabakhshi Z, Hosseinpour S. Impact of malocclusion severity on oral health - related quality of life in an Iranian young adult population. Eur $\mathrm{J}$ Dent. 2018; 12(1): 129-35. DOI: 10.4103/ejd. ejd_61_17

36. Legault L. Intrinsic and Extrinsic Motivation. In: Zeigler-Hill V, Shackleford TK, eds. Encyclopedia of Personality and Individual Differences. New York: Springer Publishing Co.; 2016. p. 1-4. 